Check for updates

Cite this: RSC Adv., 2017, 7, 32669

Received 28th April 2017

Accepted 21st June 2017

DOI: $10.1039 / c 7 r a 04803 c$

rsc.li/rsc-advances

\section{Essential oil eugenol: sources, extraction techniques and nutraceutical perspectives}

\author{
Anees Ahmed Khalil, (D)*a Ubaid ur Rahman, ${ }^{a}$ Moazzam Rafiq Khan, ${ }^{a}$ Amna Sahar, ${ }^{\text {ab }}$ \\ Tariq Mehmood ${ }^{\text {ac }}$ and Muneeb Khan ${ }^{a}$
}

Eugenol, a phytogenic bioactive component is frequently found in diversified herbal plants possessing welldefined functional attributes. Prominent sources of eugenol are clove, cinnamon, tulsi and pepper. Various extraction methods have been practiced globally for the extraction of eugenol and other nutraceutics from plants. The most extensively employed approaches in this regard include solvent extraction, hydrodistillation, microwave-assisted extraction, supercritical carbon dioxide extraction and ultrasound-based extraction. Eugenol has been approved to encompass numerous beneficial aspects against a capacious spectrum of life threatening indispositions including oxidative stress, inflammation, hyperglycemia, elevated cholesterol level, neural disorders and cancer. In addition, eugenol has also shown strong potential as an antimicrobial agent against wide ranges of pathogenic and spoilage causing microorganisms. Predominantly, the principle mechanistic approaches associated with the therapeutic potential of eugenol include its free radical scavenging activity, hindrance of reactive oxygen species' generation, preventing the production of reactive nitrogen species, enhancement of cyto-antioxidant potential and disruption of microbial DNA \& proteins. Consequently, this article is an attempt to elucidate the general properties, sources, extraction methods, therapeutic role and associated mechanisms of eugenol.

\section{Eugenol: at a glance}

Phytogenic components present in a variety of medicinal plants have been extensively used for the prevention and treatment of different lifestyle related risk factors. Traditionally, extracts of different parts of plants have been recommended to cure various complications including bronchitis, diarrhea, skin diseases, cancer, hyperlipidemia, liver ailments, hyperglycemia arthritis, cardiovascular diseases and inflammatory

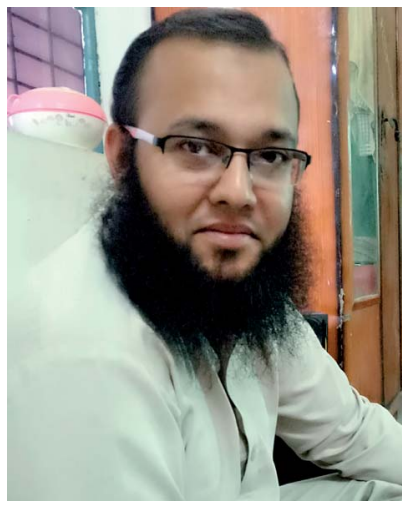

Dr Anees Ahmed Khalil is a fresh Ph.D. graduate from National Institute of Food Science and Technology, University of Agriculture, Faisalabad. His research interests are therapeutic and nutraceutical properties of fruits and vegetables. He has done his Ph.D. on utilization of pomegranate fruit waste as value added drink. Currently, he is the author of 4 impacted international research publications. Additionally he is also working on different research \& review articles and international book chapters.

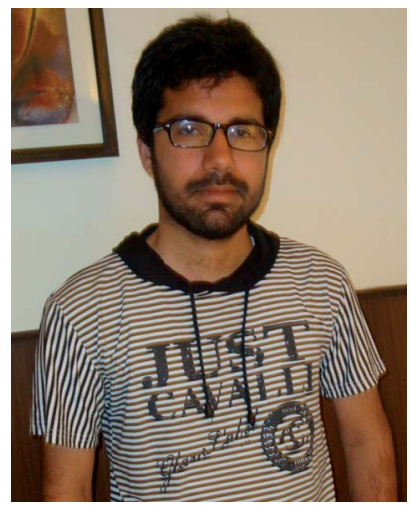

Ubaid ur Rahman is a Ph.D. Scholar at National Institute of Food Science and Technology, University of Agriculture, Faisalabad. Currently he is working on exploring the potential of various spectroscopic and molecular approaches for predicting meat quality and microbial safety. He has authored 9 international impacted research and review articles, four international book chapters and 34 conference papers. Additionally, several book chapters and research \& review articles are in pipeline. 
disturbances. The functionality of these plants is proposed due to the presence of a plethora of bioactive ingredients found in them. The most common plant based functional components include sterols, flavonoids, phenols, tocopherols and organic acids that possess tangible health benefits and have wide applications in the development of functional and nutraceutical foods. ${ }^{1}$ This particular critique mainly emphases to the therapeutic potential of eugenol to curb commonly occurring disorders.

Eugenol is a phenolic component that can be obtained from a wide range of plant sources including clove oil, nutmeg oil, cinnamon extract and many other plants. It owns strong health promoting functions that make it a versatile natural ingredient. Eugenol was firstly extracted from the leaves and buds of Eugenia caryophyllata commonly named as clove. Currently, eugenol can also be synthesized by allylation of guaiacol with allyl chloride having the similar kind of functional property. Eugenol is present in significant amount in the extracts of numerous medicinal herbs so it has fascinated the attention of several researchers and opened up the gateway of research regarding its utilization as a medicine to cure various diseases. Eugenol is avowed to possess certain pharmacological properties including anaesthetic activity, antioxidant potential,
Table 1 General physical and chemical properties of eugenol

\begin{tabular}{ll}
\hline Properties & Description \\
\hline Class & Phenylpropanoids \\
IUPAC name & 4-Allyl-2-methoxyphenol \\
Chemical formula & $\mathrm{C}_{10} \mathrm{H}_{12} \mathrm{O}_{2}$ \\
Molecular mass & $164.2 \mathrm{~g} \mathrm{~mol}$ \\
Solubility in water & Partially soluble \\
Solubility in organic solvents & Highly soluble \\
Color & Clear to pale yellow \\
Body metabolism & Absorption via small intestine \\
Excretion and elimination & Through urination and as expired $\mathrm{CO}_{2}$
\end{tabular}

antimicrobial role, anti-inflammatory action, anti-carcinogenic effects, neuroprotective ability, hypolipidemic efficiency and anti-diabetic effectiveness. Eugenol is declared as GRAS (generally recognized as safe) by World Health Organization (WHO) and is considered as non-mutagenic. The general physical and chemical properties of eugenol are discussed in Table 1. As a result of a wide spectrum of biological and functional properties, eugenol is still proclaimed as the priority of research. Therefore, it is of significant worth to rationally

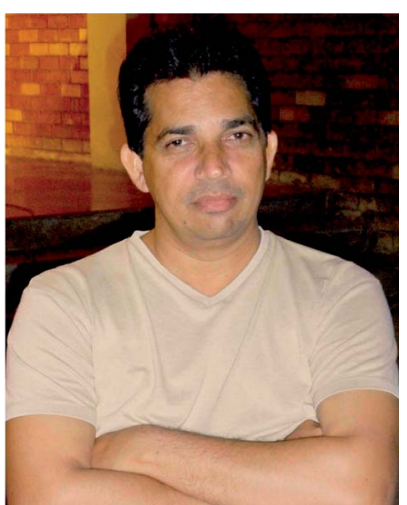

Dr Moazzam Rafiq Khan is currently an Assistant Professor in National Institute of Food Science \& Technology, University of Agriculture, Faisalabad. His research domain is food product development and functional properties of food commodities. His main area of focus is fruits and vegetables processing with special reference to value addition, waste management and formulation of functional fruit products. He also has published a number of research and review articles.

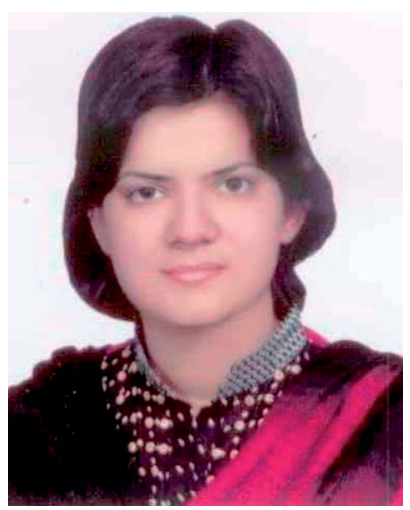

Dr Amna Sahar is working as an assistant professor in the Department of Food Engineering, University of Agriculture, Faisalabad, Pakistan. Her research interest includes development of non-destructive \& rapid methods to determine the quality \& safety of food \& food products. She has a number of impacted publications having international repute. She has produced five MSc students in food technology as main supervisor. Currently, she is supervising 2 Ph.D. and 18 M.Sc. students.

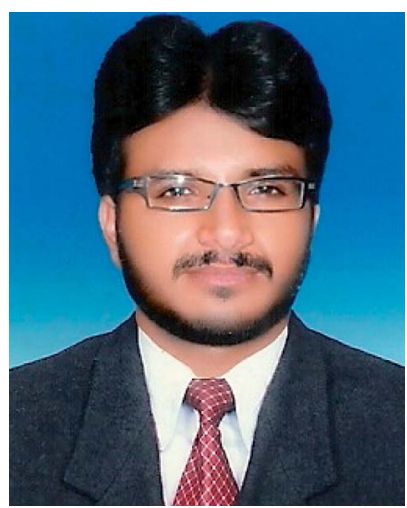

Tariq Mehmood is a Ph.D. Scholar at National Institute of Food Science and Technology, University of Agriculture, Faisalabad. He is currently working on utilization of citrus waste as functional fruit leather.

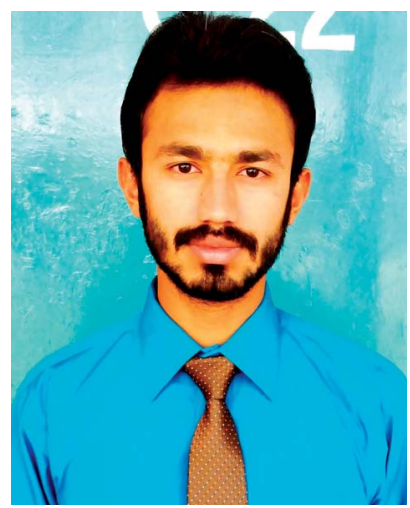

Muneeb Khan is a Ph.D. Scholar at National Institute of Food Science and Technology, University of Agriculture, Faisalabad. His research project is assessing authenticity of meat and meat products by applying spectroscopic and molecular techniques. 
confederate the research findings related to the therapeutic potential of eugenol to elucidate its importance for human health and mechanisms involved in the functionality of eugenol to obviate several lifestyle related indispositions. ${ }^{2}$

\section{Sources of eugenol}

Eugenol is found in a variety of plants including clove buds, cinnamon bark and leaves, tulsi leaves, turmeric, pepper, ginger, oregano and thyme. In addition, several other aromatic herbs including basil, bay, marjoram, mace and nutmeg are also claimed to have significant quantity of eugenol. Concentration of eugenol in some plants is depicted in Table 2. Among these plant sources, clove and cinnamon are considered as the prosperous provenances of eugenol containing 45-90\% and 20$50 \%$ eugenol correspondingly, but the major problems linked with these sources are higher cultivation costs and commercial eugenol extraction. On the contrary, other cost effective and plentiful begetters include tulsi, ginger, bay, pepper and which can be used as an alternative to clove and cinnamon. Eugenol is mostly present in the aerial parts of plants such as leaves, bark and flowers because these parts contain a considerable amount of essential oils. ${ }^{1,3}$ Tulsi leaves also contain good percentage of eugenol usually in the range of $40-71 \%$. However, concentration of eugenol in different parts of plants varies with season. Studies reveal that maximum yield of eugenol can be obtained in the fall season as compared to the summer varieties. ${ }^{4}$

\section{Extraction and isolation of eugenol}

The most common method for the isolation of eugenol is steam distillation. In the extraction and isolation process of eugenol, firstly essential oil is extracted from the plants. Afterwards, the essential oils are mixed with $3 \%$ solution of sodium or potassium hydroxide for the extraction of eugenol. This reaction results in the formation of a phenolic alkali salt. The insoluble portion of the extract is then isolated by solvent extraction or steam distillation. The remaining alkaline solution is then acidified at refrigeration temperature followed by the liberation of eugenol by employing various techniques such as fractional distillation, high pressure liquid chromatography (HPLC) or thin layer chromatography (TLC). At the end, purity of the

Table 2 Eugenol occurrence and concentration in various plants ${ }^{a}$

\begin{tabular}{lll}
\hline Source & Specified parts & $\begin{array}{l}\text { Concentration } \\
\left(\mathrm{mg} \mathrm{g}^{-1}\right)\end{array}$ \\
\hline Clove & Flowers and buds & 180 \\
Clover pepper & Fruit & 36 \\
Betel pepper & Leaves & 17.85 \\
Cinnamon & Bark & 3.52 \\
Tulsi & Leaves & $4.2-4.97$ \\
Bay & Leaves & 1.34 \\
Turmeric & Leaves and essential oil & 2.1 \\
Nutmeg & Seeds & 0.32 \\
Thyme & Shoots & 0.021 \\
${ }^{a}$ Source: (Raja et al., & 2015).
\end{tabular}

obtained eugenol is verified by employing modern spectroscopic techniques like Fourier transform infrared spectroscopy (FTIR), Fourier transform near infrared spectroscopy (FTNIR), mass spectroscopy (MS) and nuclear magnetic resonance (NMR). ${ }^{5}$ Some important methods for the extraction of eugenol from various plant sources are described herein.

\section{Solvent extraction}

Solvent extraction is one of the most common and extensively employed methods for the extraction of essential oils from plants. Accordingly, eugenol has also been extracted using various solvents like methanol, ethanol, petroleum ether and $\mathrm{N}$ hexane. The major hindrances of solvent extraction are inclusion of other soluble residues undesirable flavor changes in the food. ${ }^{6}$ However, still this method has wide applications for the extraction of eugenol and other essential oils from various aromatic herbs. In a typical solvent extraction process of eugenol from clove, the clove buds are ground and wrapped in filter paper followed by subjecting the filter paper to the extraction thimble and inserting into the reflux flask having 500 $\mathrm{mL}$ capacity. Afterwards, extraction is carried out by using a suitable organic solvent in Soxhlet apparatus. ${ }^{7}$ The process ends by concentrating the obtained extracts at $50{ }^{\circ} \mathrm{C}$ using rotary vacuum evaporator.

Several modifications have been made in the conventional solvent extraction process, which show higher efficiency as compared to the traditional method. As an instance, batch extraction process is an attractive alternative to the Soxhlet extraction. This method employs the use of reactor equipped with agitator having four blades and motor having $1200 \mathrm{rpm}$ speed. Recently, this method was studied by Garkal et al. ${ }^{8}$ who extracted eugenol from leaves of tulsi plant using methanol as solvent and reported satisfactory extraction efficiency. They further reported that extraction efficiency of eugenol was not affected by agitation speed.

\section{Hydro distillation}

Hydro-distillation is also one of the mostly used methods for the extraction of essential oils. ${ }^{9}$ During hydro distillation method, powdered sample (100 $\mathrm{g}$ dried and ground clove buds) is soaked into water. To carry out hydro-distillation, dried clove sample is taken into $500 \mathrm{~mL}$ volumetric flask and subjected to hydro-distillation for 4-6 hours. Subsequently, the volatile distillate is collected and saturated with sodium chloride following the addition of petroleum ether or other suitable organic solvent. Later, hydro and ether layers are separated and dehydrated by using anhydrous sodium sulphate. Eventually, the sample is heated in water bath at $60{ }^{\circ} \mathrm{C}$ for the recovery of ether and concentration of extract. The average yield of oil using hydro-distillation is about $\mathbf{1 1 . 5 \%}$ whereas reported eugenol concentration is 50.5-53.5\%. ${ }^{6}$ However, extraction yield can be increased by reducing the particle size of ground clove buds. ${ }^{10}$

\section{Microwave-assisted extraction of eugenol}

Traditional methods practiced for the extraction of eugenol from various plant sources are associated with several 
drawbacks like hydrolysis, thermal degradation and leaching of some fragrance components. ${ }^{\mathbf{1 1}}$ To combat these problems, several modern extraction methods have been introduced which provide high extraction yield along with reduced processing time and energy demands. Among these approaches microwave assisted extraction (MWAE) is regarded as a green extraction approach having ability to produce eugenol and other essential oils with same sensorial attributes and quality as those attained by conventional methods. This technique also provides rapid extraction rate at lower cost as compared to the traditional methods. ${ }^{12}$

Several configurations have been developed using microwave extraction process. These techniques include microwaveassisted hydro-distillation (MWHD), ${ }^{13}$ coaxial microwaveassisted hydro-distillation (coaxial MWHD), microwave assisted hydro-diffusion and gravity (MWHG) ${ }^{\mathbf{1 4}}$ and microwave steam distillation (MWSD). ${ }^{15}$ Amongst these green extraction approaches, coaxial MWHD extraction is reported to be advantageous with high savings in heating time (400\%) and energy demands (30\%). Besides, this method is safe, cost effective and has easy scale-up configuration as compared to the other microwave extraction techniques.

More recently, Gonzalez-Rivera et al. ${ }^{16}$ explored the potential of coaxial MWHD for the extraction of essential oils from various herbs (clove, lavender, sage, rosemary and fennel). In parallel, traditional hydro-distillation method was also used for comparative studies. Results of the study revealed that eugenol and other essential oil extracted through coaxial MWHD showed higher thermal stability as compared to those extracted through conventional hydro-distillation. Additionally, extraction time was quite less as compared to the conventional extraction process. Conclusively, it can be stated that microwave assisted extraction methods are quite mature to be used at industrial scale as a replacement of conventional techniques for the extraction of eugenol.

\section{Supercritical carbon dioxide extraction}

Supercritical carbon dioxide $\left(\mathrm{SC}-\mathrm{CO}_{2}\right)$ extraction is another efficient method for the extraction of eugenol from clove buds. ${ }^{17}$ The efficiency of SC-CO $\mathrm{C}_{2}$ extraction has been reported through several investigations. For example, Gopalakrishnan et al. ${ }^{\mathbf{1 8}}$ compared the efficiency of liquid and $\mathrm{SC}-\mathrm{CO}_{2}$ extraction and found higher extraction rate of clove oil using $\mathrm{SC}-\mathrm{CO}_{2}$ extraction. Likewise, Reverchon and Marrone $^{\mathbf{1 9}}$ concluded that extraction yield of eugenol can be increased by increasing the flow rate of $\mathrm{CO}_{2}$ in supercritical extraction. Additionally, Wenqiang et al. ${ }^{6}$ and Hong-Peng et al. ${ }^{20}$ conducted experiments to study the composition of clove bud oil extracted by $\mathrm{SC}-\mathrm{CO}_{2}$ and other conventional techniques (solvent extraction, steam distillation, molecular distillation) and reported very similar composition as obtained by traditional methods. Although several studies have shown the potential of $\mathrm{SC}-\mathrm{CO}_{2}$ extraction as an efficient tool for the extraction of clove oil however studies on optimization of the yield of the $\mathrm{SC}-\mathrm{CO}_{2}$ extracted eugenol are scanty. Hence, further studies are needed to highlight the potential of $\mathrm{SC}-\mathrm{CO}_{2}$ extraction method for the recovery of eugenol from the clove bud oil.

\section{Ultra-sound assisted extraction of eugenol}

Even though several non-conventional techniques successfully control the drawbacks associated with the use of traditional methods however they may differ in extraction effectiveness. Recently, another green extraction method called ultrasound (US) extraction has been introduced that has significantly accelerated the extraction process and reduced the energy demand. Other advantages linked with the use of US extraction are easy handling of extract, rapid execution, no residues, high yield, eco-friendly, enhanced quality and prevention of extract degradation. ${ }^{21}$

Alexandru et $a .^{22}$ assessed the efficiency of ultrasoundassisted extraction and traditional maceration for the extraction of clove oil. Purposely, they selected three different flow modes $\left(450,900,1350 \mathrm{~mL} \min ^{-1}\right)$ for US extraction and reported higher extraction rate at $1350 \mathrm{~mL} \mathrm{~min}^{-1}$. Similarly, Tekin et $a .^{23}$ employed US extraction for the extraction of clove essential oils using central composite design (CCD). The independent variables of the study were temperature $\left(32-52{ }^{\circ} \mathrm{C}\right)$, extraction time (30-60 min) and plant concentration (3-7\%) while the dependent variable was clove extract. The frequency of the ultrasound bath was fixed at $53 \mathrm{kHz}$. The findings of the study exposed that extract yield was highly influenced by temperature. The obtained extract was composed of eugenol, $\alpha$ caryophyllene and 2-methoxy-4-(2-propenyl)phenol acetate. These investigations concluded that ultrasound-assisted extraction is an effective tool that can pave the road for the setup of commercial applications of this method.

\section{Validated pharmacological properties of eugenol}

Numerous investigations have documented the therapeutic potential of eugenol that highlights its importance as one of the principal bioactive components having several health promoting functions. The pharmaceutical functions of essential oils extracted from various plants have also thought to be due to the presence of eugenol. ${ }^{24}$ A number of studies have been carried out in order to explain the mechanism involved behind the therapeutic activity of eugenol. On a general node, mechanistic approach of functional activeness of eugenol proposed through several trials is its free radical scavenging activity, prevention of reactive oxygen species (ROS) \& reactive nitrogen species (RNS) generation, DNA and protein damage, and elevation of cellular antioxidant potency. ${ }^{25}$ Eugenol is vindicated to be effective against a number of lifestyle related threats including nervous disorders, digestive complications, reproductive derangements, blood cholesterol irregularity, hyper-tension, elevated blood glucose level, microbial infections, inflammatory actions and carcinogenesis. ${ }^{26}$ This section will summarize the ameliorative vivacity of eugenol to encounter several metabolic ailments and mechanisms associated with the functional and health promoting attributes of eugenol (Table 3).

\section{Antioxidant activity of eugenol}

Many human related disorders like cancer, diabetes, arthritis, Parkinson's disease, AIDS and Alzheimer's complications are 
Table 3 Molecular mechanisms of eugenol in various nutraceutical properties

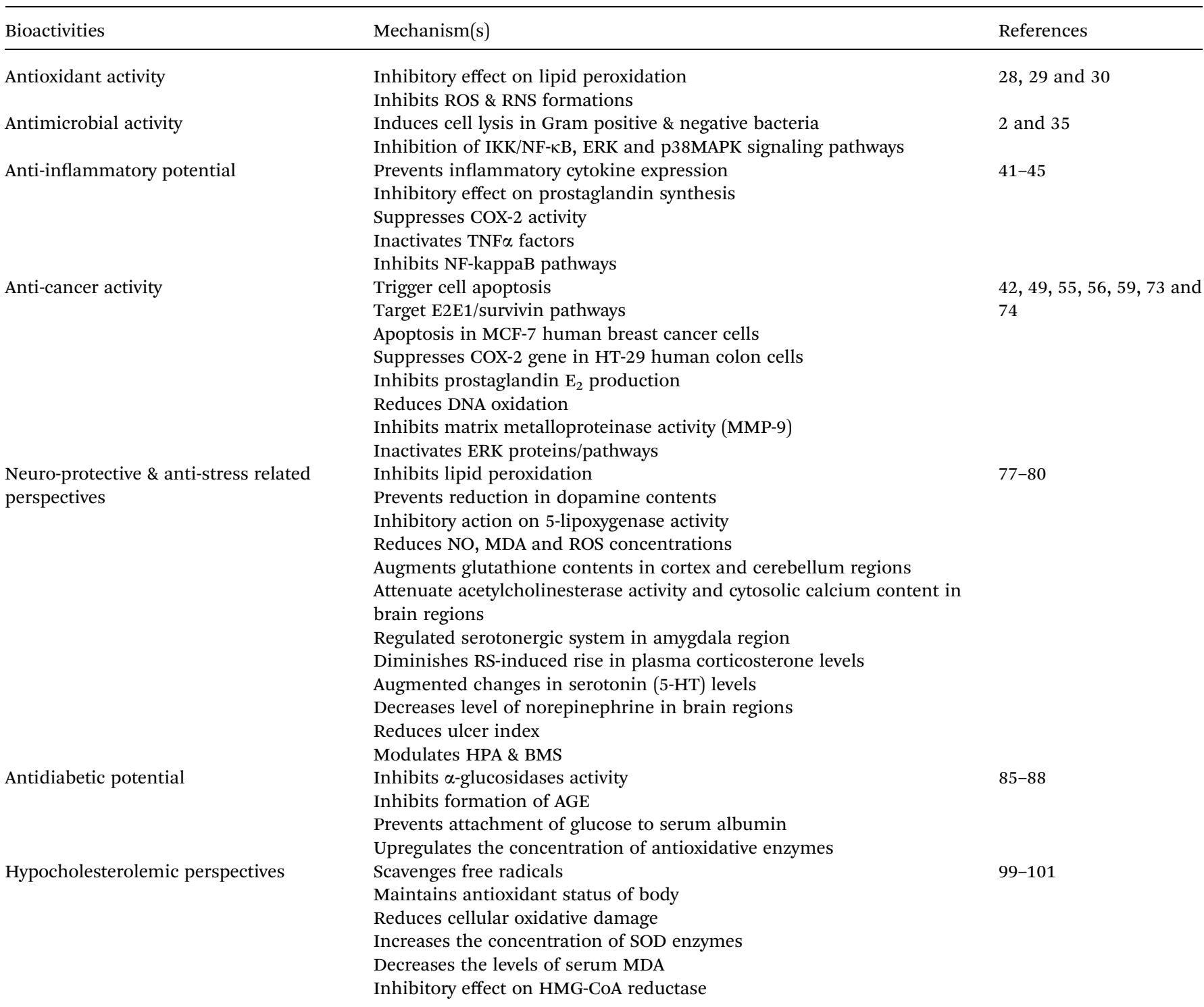

prompted and exaggerated due to redundant group of the free radicals. Reports have indicated that fruits and vegetables containing cache of phytonutrients like polyphenols, flavonoids and anthocyanin are observed to be efficacious in scavenging the free radicals. ${ }^{27}$ Eugenol, a potent phenolic component in clove oil is chiefly responsible for its antioxidant and free radical scavenging activity. Antioxidant power of eugenol can be elucidated by forming complexes with reduced metals. Potent inhibitory effect on lipid peroxidation by isoeugenol and eugenol is administrated to be due to eradication of free radical and formation of iron-oxygen chelate complex, by keeping iron and copper at a reduced state respectively. ${ }^{28}$

In an experimental trial, Gulcin ${ }^{29}$ revealed the antioxidant potential of eugenol and reported $96.7 \%\left(r^{2}=0.9319\right)$ inhibitory effect on lipid peroxidation of linoleic acid emulsion at a concentration of $15 \mu \mathrm{g} \mathrm{mL}^{-1}$ comparable to butylated hydroxytoulene (BHT). Same study suggested DPPH (2,2-diphenyl-1-picrylhydrazyl) free radical scavenging activity having lowest $\mathrm{IC}_{50}$ value of $16.06 \mu \mathrm{g} \mathrm{mL}{ }^{-1}\left(r^{2}=\right.$ 0.9823). This scavenging effect of eugenol is due to presence of allyl group in its structure. Another study by Gulcin et al. ${ }^{30}$ elucidated $93.3 \%$ and $97.9 \%$ inhibition on lipid peroxidation of linoleic acid emulsion at 20 and $60 \mu \mathrm{g} \mathrm{mL} \mathrm{mL}^{-1}$ correspondingly.

Additionally, Lee and Shibamoto ${ }^{31}$ showed that aromatic extract containing eugenol as major bioactive ingredient from clove inhibited the hexanal oxidation at a level of $50 \mu \mathrm{g} \mathrm{mL}{ }^{-1}$ for 30 days. By gas chromatography/mass spectrometry (GC-MS) analytical technique twenty two different compounds were quantified in aromatic extracts, implying $24.37 \mathrm{mg} \mathrm{g}^{-1}$ and $2.35 \mathrm{mg} \mathrm{g}^{-1}$ of eugenol and eugenyl acetate to be the key ones. Eugenyl acetate and eugenol repressed $79 \%$ and $88 \%$ malonaldehyde formation from cod liver oil@160 $\mu \mathrm{g} \mathrm{mL}{ }^{-1}$. 


\section{Antimicrobial activity of eugenol}

Microbial food-borne illness is currently one of the foremost concerns for food safety authorities, food processing industry and ultimately the consumers. Simultaneously, consumers are concerned regarding the safety aspects of synthetic and artificial food preservatives. Dissemination of methicillin resistant Staphylococcus aureus (MRSA) one of the antibiotic resistant pathogen has provoked researchers to revive the quest for antimicrobial complexes from natural plant sources. Since ancient times, herbs and spices are supplemented in food system, not only to enhance flavoring profile, but also as food preservative and folk medicine. Due to their diversified biological and biochemical functions, plant phytogenic compounds have established a great deal of attention, over past few decades. ${ }^{32}$

Clove oil polyphenol eugenol illustrates potent antibacterial potential against numerous strains of Gram-positive (Enterococcus faecalis, Staphylococcus epidermidis, Streptococcus pyogenes, Staphylococcus aureus, Streptococcus pneumonia, Listeria monocytogenes, Bacillus cereus, Bacillus subtilis) and Gramnegative (E. coli, Proteus vulgaris, Salmonella choleraesuis, Salmonella typhi, Pseudomonas aeruginosa, Helicobacter pylori and Yersinia enterocolitica) bacteria. Eugenol damages cell membrane and cell wall, inducing cell-lysis in Gram negative and Gram positive bacteria resulting in leakage of intracellular fluid along with lipid and protein contents. ${ }^{33,34}$ Strong eradicative and inhibitory effect of eugenol has been documented according to in vitro and in vivo studies on biofilms. At concentration of $0.5 \times$ MIC (minimum inhibitory concentration) $50 \%$ inhibition was recorded in case of biofilms formed by methicillin resistant Staphylococcus aureus (MRSA) and methicillin susceptible Staphylococcus aureus (MSSA) strains. Minimum biofilm eliminating concentration (MBEC) of already formed biofilms was reduced to $99 \%$ by collective application of both carvacrol and eugenol. ${ }^{2}$

Eugenol has potentiality to constrain viral infection and replication categorically against herpes simplex viruses i.e. HSV1 and HSV-2 exhibiting IC $_{50}$ values between $16.2 \mu \mathrm{g} \mathrm{mL}^{-1}$ and $25.6 \mu \mathrm{g} \mathrm{mL} \mathrm{m}^{-1}$, explored by plaque reduction assay (PRA). Eugenol has been validated to be adequate against herpes simplex virus-1 (HSV-1) clinical isolates. ${ }^{35}$ Eugenol inhibits influenza-A virus's replication and autophagy; by inhibiting the initiation of IKK/NF- $\kappa$ B and ERK, p38MAPK signal pathways. ${ }^{2}$

\section{Anti-inflammatory potential of eugenol}

Inflammation is known as adaptive immunity response of body that is stimulated by noxious stimuli and other various conditions, for instance tissue injury and infection. ${ }^{36}$ It could either be classified as acute or chronic inflammation. Acute inflammation also known to be physiological inflammation is a valuable and constructive host response against tissue damage, but if in time remediation is delayed, it leads to metabolicassociated syndromes as cancer, inflammatory bowel disease (IBD) and rheumatoid arthritis. It is an initial response that results in movement of macrophages and neutrophils from blood stream into infected tissues. ${ }^{37}$ Alternatively, chronic inflammation is related to tissue malfunctioning mainly due to persistent exposure to noxious stimuli that results in changes allied with the development of cancer through attraction of bioactive lipids such as eicosanoids, soluble pro-inflammatory mediators TNF- $\alpha$ and transcription activation factors NF$\kappa \mathrm{B} .^{38,39}$ In the last decade, nutraceutical prospects of eugenol and its derivatives have been exploited by scientists to formulate novel drugs from plant origin having low drug toxicity, mainly those implicating anti-inflammatory potential, to be used in treatment of various maladies. ${ }^{\mathbf{4 0}}$

The principal methoxyphenol of clove oil; eugenol has documented anti-inflammatory potential. Eugenol suppresses cyclooxygenase (COX)-2 expression and tumor necrosis factor (TNF) signaling, whereas eugenol oligomers avert inflammatory cytokine expression in macrophages and NF-kappaB (nuclear factor-kappaB) activation. ${ }^{41}$ The anti-inflammatory mode of action of eugenol is mainly due to its inhibitory effect on prostaglandin synthesis and neutrophils/macrophages chemotaxis. $^{42}$

According to findings of Koh et al., ${ }^{43}$ eugenol at concentration 5-500 $\mu \mathrm{M}$ significantly accelerated IL-8 (interleukin-8) production in HGF (hepatocyte growth factor) cells, resulting insubstantial stimulation at $5 \mu \mathrm{M}$ and significant inhibition at $500 \mu \mathrm{M}$. Another study concluded beneficial effect of eugenol administrated at 5 and $10 \mathrm{mg} \mathrm{kg}^{-1}$ per B.W. against lipopolysaccharide (LPS) induced acute lung injured (ALI) mice, for this purpose $0.5 \mathrm{mg} \mathrm{kg}{ }^{-1}$ LPS was intratracheally infused. Examination of lung tissues and bronchoalveolar lavage fluid (BALF) suggested anti-inflammatory effect due to reduced production of pro-inflammatory cytokines. ${ }^{\mathbf{4 4}}$

Additionally, in vitro studies revealed that clove oil polyphenol inhibits nuclear factor- $\kappa \mathrm{B}(\mathrm{NF}-\kappa \mathrm{B})$ activation in lipopolysaccharides initiated macrophages induced by inactivated cyclooxygenase activity (COX-2) and tumor necrosis factor $(\mathrm{TNF} \alpha)$. Cyclooxygenase activity is prompted by LPS, cytokines and growth factors. ${ }^{42}$ During pulmonary inflammation in mouse, elevated TNF- $\alpha$ and neutrophils were significantly reduced by eugenol at a dose of $160 \mathrm{mg} \mathrm{kg}^{-1}$ per body weight. It also protected against chemically induced dysfunction of macrophages and balanced the pro-inflammatory mediators. ${ }^{45}$

Further clinical studies are required to authenticate the use of eugenol and its other active derivatives as anti-inflammatory agents on dendritic cells, along with their modulating effects on cytokines and autoimmune inflammatory diseases. Eventually, results from these clinical trials would significantly improve the immune-protective application of eugenol.

\section{Anti-cancer activity of eugenol}

Cancer is broadly known as rampant cell division that eventually causes cell aggregation leading to tumors formation. Cancer is documented as second leading single reason of mortality claiming annual death toll of six million lives globally. ${ }^{46}$ Numerous factors are involved in onset of cancers, for instance smoking, ingestion of heavy metals \& pesticides, genetic mutations and indeed lack of safe \& healthy diet. ${ }^{47}$ Inflammation results in cellular aggregation due to improper functioning of signaling pathways which is related to 
pathogenesis of cancers. ${ }^{48}$ Treatment of cancer lies in inhibition of cell propagation and annihilation of malicious cells. ${ }^{49}$

Recent clinical studies of medicinal plants used in numerous traditional medicines have triggered the invention of various chemotherapeutic drugs, like camptothecin, vinblastine, taxol and vincristine. ${ }^{50}$ Several scientific studies have pointed out chemo-protective potential of eugenol against different form of cancers. ${ }^{51}$ In vitro studies have proven the potential of eugenol and their chemically synthesized derivatives against gastric cancer, colon cancer, leukemia, breast cancer, prostate cancer, melanoma and skin tumors etc. ${ }^{49}$

Breast cancer is the most prevalent type of malignant cancer among women and is ranked fourth common reason of cancer related deaths in the world. ${ }^{52}$ Mammary homeostasis depends upon balance among cycles of proliferating mammary epithelial cells and their death through the process of apoptosis. ${ }^{53}$ Risk associated to instinctive breast cancer is linked to elevated escalation of mammary epithelial cells that is eventually responsible for the genetic alteration. Eugenol associated biphenyl (S)-6,6'-dibromo-dehydrodieugenol elicits particular anti-proliferative activity on neuro-ectodermal tumor cells by partially triggering apoptosis. ${ }^{54}$ Vidhya and Devaraj ${ }^{55}$ provided some evidence that eugenol has anticancer potential in human breast cancer cells (MCF-7) as epoxide form of eugenol is considered as anticancer drug regarding induction of apoptosis in MCF-7 cells. Eugenol repressed growth of human breast cancer cells by initiation of cell death both in time and dose dependent manner. ${ }^{56}$

Essential oils being extracted by hydro distillation of roots and barks of Uvariodendron angustifolium containing $85.3 \%$ and $68.3 \%$ of methyl eugenol respectively, unveiled cytotoxic potential in MCF-7 cancer cells. ${ }^{57}$ Cytotoxic properties of eugenol and its related dimers were may be due to interaction of lipophilic radical with the cell membrane and this cytotoxic characteristic was observed highest in dehydrodiisoeugenol followed by di-isoeugenol, isoeugenol, eugenol and least by biseugenol. ${ }^{58}$ Both in vitro and in vivo studies on anti-breast cancer activity of eugenol have revealed that it could augment the treatment of human breast cancer by targeting the E2F1/ survivin pathway. ${ }^{59}$

Inducible cyclooxygenase (COX-2) inhibitors have been considered as cancer chemo-preventive and anti-inflammatory agents. According to findings of Kim et al., ${ }^{42}$ eugenol at concentration $10 \mu \mathrm{g} \mathrm{m \textrm {m } ^ { - 1 }}$ was found to significantly inhibit (98.3\%) prostaglandin $\mathrm{E}_{2}$ production in LPS-activated (lipopolysaccharide) mouse macrophage cells (RAW264.7). Isolated eugenol not only suppressed COX-2 genes in HT-29 human colon cancer cell line, but also exhibited inhibition of PGE-2 considerably, having $\mathrm{IC}_{50}$ value as $0.37 \mu \mathrm{M}$. They also revealed that eugenol inhibited the propagation of HT-29 cells and the mRNA expression of COX-2 gene. Remedies for colon cancer through administration of eugenol resulted in decreased concentration intracellular non-protein thiols. Additionally, DNA fragmentation caused by amplification of reactive oxygen species (ROS) is considered as a core reason for apoptosis in eugenol-subjected colon cancer cells. Eugenol not only transmitted apoptotic signal through reduction of non-protein thiols resulting in decreased potential of mitochondrial membranes, eventually leading to increased production of ROS. ${ }^{60,61}$ Similarly, an earlier investigation by Jaganathan et al. ${ }^{62}$ suggested that intraperitoneal administration of eugenol at a concentration of $100 \mathrm{mg} \mathrm{kg}^{-1}$ inhibited the growth of solid carcinoma and Ehrlich ascites by 24.35 and $28.88 \%$, respectively.

Novel strategies in cancer prevention have initiated the use of eugenol as a potential chemotherapeutic agent. Synergistic effect of eugenol with chemo-preventive drugs has been reported to reduce the drug toxicity on normal cells and augment the cytotoxicity of administrated synthetic agents. ${ }^{63}$ Purposely, to mitigated the effect of drug induced resistance various phenyl-propanoids including eugenol was examined in combination with 5-fluorouracil; an anticancer drug against human cervical cancer cell line (HeLa cells). Among all investigated phenyl-propanoids, eugenol explicated maximum cytotoxicity and reduced hemolytic activity validating its use as a chemoprotective agent without any adversative toxicity. ${ }^{64,65}$ Moreover, synergistic interactions of eugenol and gemcitabine impelled apoptosis and growth inhibition at lower concentrations as compared to individual agents. Eugenol $\left(150 \times 10^{-6} \mathrm{M}\right)$ and gemcitabine $\left(15 \times 10^{-6} \mathrm{M}\right)$ reduced cell viability from $84 \%$ (eugenol) and $51 \%$ (gemcitabine) to $47 \%$ in combination. ${ }^{66,67}$

Currently, chemo-protective agents being practiced to cure malignant melanoma; typically the most antagonistic skin cancer occurring in melanocytes are unsatisfactory. ${ }^{68,69}$ Pisano et $a l .{ }^{54}$ conducted in vitro trials to assess anti-proliferative potential of eugenol and its six derivatives against melanoma cells lines. They suggested inhibitory mode of action of eugenol as it causes cell cycle arrest and induces apoptosis. Likewise, anti-proliferative mode of action of eugenol and iso-eugenol against melanoma cancer cells has also been examined in B16 xenograft model, resulting decrease $(40 \%)$ in tumor size due to production of ROS having inhibitory effect on DNA synthesis. $^{70,71}$

In an experimental trial Koh et al. $^{72}$ suggested the induction of non-apoptotic cell death by clove oil bioactive ingredient, eugenol. Cytotoxic concentrations of eugenol resulted in reduction of ATP utilization of oxidative stress and an increase in the polyamines and glycolytic metabolites, in normal oral cells and oral squamous cell carcinoma. Another group of researchers have highlighted the inhibitory potential of eugenol against expression of matrix metalloproteinase (MMP-9) activity in PMA-stimulated HT1080 cells via inactivation of ERK proteins. Consequently, they evaluated that eugenol from cloves, explicitly revealed highest inhibitory effect on hydrogen peroxide $\left(\mathrm{H}_{2} \mathrm{O}_{2}\right)$ than other ROS (reactive oxygen species), and was able to halt lipid peroxidation and DNA oxidation, induced by hydroxyl radical. Therefore, eugenol could be accessible as an outstanding agent for prevention of metastasis associated to oxidative stress. ${ }^{73,74}$ Eugenol and its allied derivatives require further investigation in order to be considered as chemotherapeutic.

\section{Neuro-protective \& anti-stress related perspectives of eugenol}

Eugenol, an indispensable component predominantly found in spices such as nutmeg, clove, cinnamon, basil etc. has been 
stated to possess potent neuro-protective and anti-stress related properties. Evidently, eugenol acts as neuro-protective agent against amyloid- $\beta$ peptide, ischemia \& excito-toxicity by improving neuronal complications and inhibiting the transmission in sciatic nerves. ${ }^{75}$ Ancient pharmacopoeias exposed that majority of herbal medications designated for Alzheimer disease (AD) comprised of a herb Acori Graminei Rhizoma which was rich in eugenol. ${ }^{76}$ In vitro cell model studies have revealed inhibitory activity of eugenol on 5-lipoxygenase and ameliorating effect against oxidative \& excito-toxic injured neuronal cells. Further, eugenol significantly inhibited lipidperoxidation and prevented reduction in dopamine contents in experimental rats. ${ }^{77}$

Several studies have been performed to study the neuroprotective and anti-stress related potential of eugenol. For instance, Prasad and Muralidhara ${ }^{78}$ investigated the neuroprotective effectiveness of eugenol and iso-eugenol against acrylamide (ACR) induced neuropathy model in male albino rats. They intraperitoneally administrated ACR $\left(50 \mathrm{mg} \mathrm{kg}^{-1}\right.$ per B.W.) thrice a week for 5 consecutive weeks for the induction of neuropathy. Supplementation of functional ingredient eugenol and iso-eugenol to ACR-induced rats $\left(10 \mathrm{mg} \mathrm{kg}^{-1}\right.$ per B.W.) for five weeks resulted in noticeable enhancement in behavioral index gait score. Momentously, both active ingredients reduced oxidative stress markers i.e. nitric oxide (NO), malondialdehyde (MDA) \& reactive oxygen species (ROS) and augmented the glutathione concentrations in brain [cortex $(\mathrm{Ct})$, cerebellum $(\mathrm{Cb})]$ as well as in sciatic nerve (SN) regions. Furthermore, they effectually diminished the acetylcholinesterase activity, levels of cytosolic calcium and dopamine in brain regions. Conclusively, they were of a view that eugenol and iso-eugenol have tendency to curtail acrylamide induced neuropathy in rats and therefore possibly could be used as a diet based regime to attenuate various forms of neuropathy in human beings.

Additional studies illuminate the protecting potential of eugenol by modulation of hypothalamic pituitary adrenal cortex (HPA) axis and brain mono-aminergic pathways against restraint stress irritable bowel syndrome (RS-IBS) in rats. Oral administration of eugenol $\left(50 \mathrm{mg} \mathrm{kg}^{-1}\right)$ reduced $(80 \%)$ restraint stress induced upsurge in fecal pellets comparable with the medication of ondansetron. Eugenol regulated serotonergic system in amygdala \& PFC and extenuated (80\%) RS-induced rise in levels of plasma corticosterone. Alongside, eugenol also deflated RS-induced alterations in levels of norepinephrine and elevated antioxidant immune system in all regions of brain. ${ }^{79}$

Stress is foremost psychopathological reason for numerous psychological and mental impairments. Hypothalamic pituitary adrenal (HPA), sympatho-adrenal and brain monoaminergic systems (SA \& BMS) mediates various psychological and physiological responses in stress conditions. Eugenol is stated to significantly moderate brain functions by regulating the release of neurotransmitters. Garabadu et $a .^{80}$ assessed the anti-stress potential of eugenol on rats that were subjected to $4 \mathrm{~h}$ restraint stress model. Exposure to stress not only elevated the ulcer index but also increased the plasma norepinephrine and corticosterone levels. However, eugenol administration for 7 days showed significant effect on hypothalamic pituitary adrenal (HPA) axis by reducing the stress-induced upsurge in ulcer index and plasma corticosterone levels. Moreover, eugenol also augmented the stress-induced changes in serotonin (5-HT) levels in all regions of brain, while decrease in norepinephrine levels was also observed in all portions of brain except for hippocampus. Outcomes of this study suggested anti-stress activity of eugenol is mainly due to modulation of hypothalamic pituitary adrenal (HPA) and brain monoaminergic systems (BMS). Several research mediations suggested the importance of eugenol as neuro-protective agent which could further be used in stress related pathological conditions.

\section{Anti-diabetic potential of eugenol}

Abnormalities in glucose metabolism result in degenerative disease broadly known as diabetes mellitus (DM). It is mostly associated with reduced production of pancreatic insulin and or passivity of body organs to insulin resulting in hyperglycemia, a pre-condition stage for onset of diabetes. ${ }^{\mathbf{8 1}}$ Abnormalities in machinery of glucose metabolism and persistent efforts of physiological system to revert metabolic discrepancies pose an extra exertion on hormones secreted by endocrine system eventually causing disturbance in endocrine control. Disruption of endocrine control infuriates the metabolic deterioration by varying glucose metabolic enzymes that induces hyperglycemia. $^{\mathbf{8 2}}$ Prolonged hyperglycemia precedes assistance in disintegration of $\beta$-secreting insulin cells, commonly known as glucose toxicity. ${ }^{83}$ Prevalence of hyperglycemia in diabetic subjects not only causes impairment in nucleic acids, cellular proteins and membrane lipids, but also escalates the rate of outset of respective ailment.

Nowadays, researchers have shifted their preference towards diet based régime to cure various metabolic ailments owing to presence of nutraceutical agents mainly responsible for augmenting potentials against diseases. Amongst various strategies to combat diabetes, diet plays a vital part in maintaining blood sugar level, hyper-glycosylation of biologically active molecules linked with various metabolic pathways and inhibition of pathologies. For this purpose, innumerable polyphenolic molecules present in various food commodities irrespective of plant or animal origin are incessantly being exploited to assess their therapeutic potential in precluding and/or controlling diabetes. ${ }^{84}$ Phenolic acids known to be secondary metabolites are predominantly found in several fruits, vegetables and spices. Various epidemiological investigations have illustrated the positive relationship among the utilization of phenolic rich diet and prevention of diabetes. ${ }^{85}$

Various experiments have shown that eugenol is the key bioactive molecule present in spices with anti-diabetic potential. In this context, Srinivasan et $a .^{86}$ assessed the hypoglycemic properties of eugenol by determining the activities of main enzymes associated to glucose metabolism in streptozotocin induced (40 $\mathrm{mg} \mathrm{kg}^{-1}$ per B.W.) male diabetic rats. The normal control group (I) was vehicle treated (olive oil), group II (normal rats) subjected to eugenol (10 $\mathrm{mg} \mathrm{kg}^{-1}$ per B.W.), group III was (diabetic control) while group IV, V and VI comprised of 
diabetic rats that were administrated to $2.5,5.0$ and $10 \mathrm{mg} \mathrm{kg}^{-1}$ per body weight (B.W.) of eugenol. Serum biochemistry after 30 days showed that all doses of eugenol significantly $(p<0.05)$ declined plasma glucose and increased insulin level. However, dose of $10 \mathrm{mg} \mathrm{kg}^{-1}$ per B.W. eugenol momentously reduced the concentration of blood glucose (70\%) and glycosylated hemoglobin $(25.70 \%)$ whereas an increase in plasma insulin level $(46.15 \%)$ was observed as compared to diabetic control at the termination of experimental trial. Furthermore, activities of various enzymes involved in carbohydrate metabolism increased for instance hexokinase $(62.25 \%)$, pyruvate kinase (68.57\%), glucose-6-phosphate dehydrogenase $(31.05 \%)$ while reduction in levels of glucose-6-phosphatase (24.45\%), fructose1,6-bisphosphatase (32.55\%), AST (27.12\%), ALT (39\%), ALP $(41.70 \%)$, creatine kinase $(38.57 \%)$ and blood urea nitrogen (34.01\%) of experimental diabetic rats was observed due to administration of eugenol. Additionally, orally administrated eugenol elevated the levels of hepatic glycogen demonstrating the anti-hyperglycemic capabilities in diabetic rats.

Later, Tahir et $a .^{87}$ examined anti-diabetic potential of essential oils from clove and cumin and their respective emulsions in dose dependent manner (1-100 $\left.\mu \mathrm{g} \mathrm{mL}^{-1}\right)$ by application of $\alpha$-amylase inhibitory assay. Highest anti-diabetic activity was noticed at maximum dose i.e. $100 \mu \mathrm{g} \mathrm{mL} \mathrm{m}^{-1}$ for both experimented clove and cumin essential oils. In this experiment, five emulsions were formulated using different concentrations (5-25\%) of each clove and cumin essential oils. Results of $\alpha$-amylase inhibition assay unveiled maximum anti-diabetic potential $(83.09 \%$ \& $95.30 \%$ ) in emulsions containing $25 \%$ of cumin and clove essential oils, respectively. Besides this, bioactive components responsible for potent anti-diabetic activity of clove (eugenol; 18.70\%) and cumin ( $\alpha$-pinene $18.80 \%$ ) essential oils were quantified using GC-FID. Furthermore, Singh et al. ${ }^{\mathbf{8 8}}$ proposed dual anti-diabetic mechanism of eugenol; primarily by inhibiting alpha-glucosidases followed by preventing formation of advanced glycation end products (AGE). Moreover, there is a dire need for various community based trials and clinical studies to comprehend the antidiabetic and hypoglycemic potential of eugenol and its derivatives.

\section{Eugenol: a hypo-lipidemic agent}

Hyperlipidemia owing to its positive connection between lipids related abnormalities and cardiovascular diseases (CVD) is known to be the most vital socio-economic issue in common people along with health professionals. ${ }^{89}$ Sedentary lifestyle, along with intake of fat rich diet and less physical activity, expressively contributes in onset of hyperlipidemia and CVD. ${ }^{90}$ Elevated levels of low density lipoprotein cholesterol (LDL-c) causing atherogenesis and toxicity to vascular tissues, amass in extracellular sub-endothelial regions of arteries resulting in hypertension, diabetes, atherosclerosis, obesity and inappropriate functioning of vital body organs like heart, liver and kidneys. ${ }^{91}$ Scientific trials have publicized that mortality and morbidity linked with CVDs could be alleviated by reducing the dietary intake of lipids. ${ }^{92}$ Reduction in LDL-c levels has also been found to reduce the propagation of cardiovascular complications and ameliorate atherosclerotic conditions. ${ }^{\mathbf{9 3 9 4}}$

Reactive oxygen species (ROS) results in progression of oxidative stress conditions responsible for proliferation of various chronic diseases such as coronary heart disease (CHD) and atherosclerosis. ${ }^{95}$ Increased production of free radicals in body usually escorts disturbance in antioxidant status, leading to cellular oxidative damage. ${ }^{\mathbf{9}}$ Dyslipidemia is stated to be allied with oxidative stress conditions originated with the increased formation of ROS, resulting in improper functioning of the antioxidative defense system. ${ }^{97}$ Diet modulation is the foremost choice to address atherosclerosis and dyslipidemia. The propagation of atherosclerotic conditions is significantly assuaged through if the diet comprising of antioxidants and cholesterol lowering phytochemicals. In the last two decades, rice bran has gained special attention by the researchers for its anti-atherogenic, cholesterol lowering and free radical scavenging potential.98

Many studies have been conducted to assess the antihypercholesterolemic anti-atherogenic potential of eugenol. In this context, Venkadeswaran et al. ${ }^{99}$ evaluated antihyperlipidemic potential of eugenol in intraperitoneally injected Triton WR-1339 (300 mg kg-1 per B.W.) induced hyperlipidemic Wister male rats. Eugenol administration reduced LDL-cholesterol (79.48\%), total cholesterol (55.88\%) and triglycerides (64.30\%) levels. The hyperlipidemia ameliorating potential of eugenol was comparatively effective as that of lovastatin; a lipid lowering drug. Additionally, hypercholesterolemic rats subjected to eugenol showed significant reduction in activities of ALP, LDH and ALT enzymes as compared to positive controls.

In hypercholesterolemia, concentration of superoxide dismutase (SOD) decreases and that of malondialdehyde (MDA) increases rapidly in serum profile. Munisa et al. ${ }^{\mathbf{1 0 0}}$ examined the effectiveness of cloves leaf extract mainly containing eugenol as bioactive phytochemical against SOD and MDA profiles in hypercholesterolemic rats. They were of a view that cloves leaf extract significantly reverted the levels of MDA and SOD in normal ranges. Similarly, Jin and $\mathrm{Cho}^{101}$ also illustrated hypocholesterolemic potential of clove extract (eugenol) in hyperlipidemic zebrafish model. They concluded that clove essential oil reduced serum cholesterol and triglycerides up to 68 and $80 \%$, respectively. Besides, without outcomes of clinical trials, it is not recommended to suggest eugenol and its derivatives to patients suffering from dyslipidemia.

\section{Conclusion}

This review article explicates the effectiveness of eugenol as a therapeutic tool that can be incorporated to various foods and herbal medicines for contending considerable metabolic disorders. It also contains considerable antimicrobial properties and can be employed to inhibit the growth of microbial populations in many foods. Additionally, derivatives of eugenol have unlocked a new era in the domain of pharmacology, kindling the research interests on this compound. Nevertheless, more studies are required to specify the dosage level of eugenol 
for various functional applications and to explore several other hidden potentials of eugenol for the betterment of mankind.

\section{Conflicts of interest}

Authors declare no conflicts of interest.

\section{References}

1 P. Prakash and N. Gupta, Therapeutic uses of Ocimum sanctum Linn (Tulsi) with a note on eugenol and its pharmacological actions: a short review, Indian J. Physiol. Pharmacol., 2005, 49, 125-131.

2 M. R. C. Raja, V. Srinivasan, S. Selvaraj and S. K. Mahapatra, Versatile and synergistic potential of eugenol: a review, Pharm. Anal. Acta, 2015, 6, 5, DOI: 10.4172/21532435.1000367.

3 G. P. Kamatou, I. Vermaak and A. M. Viljoen, Eugenolfrom the remote Maluku Islands to the international market place: a review of a remarkable and versatile molecule, Molecules, 2012, 17, 6953-6981.

4 M. K. Yadav, S. W. Chae, G. J. Im, J. W. Chung and J. J. Song, Eugenol: a phyto-compound effective against methicillinresistant and methicillin-sensitive Staphylococcus aureus clinical strain biofilms, PLoS One, 2015, 10, e0119564.

5 S. K. Mahapatra, S. P. Chakraborty, S. Majumdar, B. G. Bag and S. Roy, Eugenol protects nicotine-induced superoxide mediated oxidative damage in murine peritoneal macrophages in vitro, Eur. J. Pharmacol., 2009, 623, 132-140.

6 G. Wenqiang, L. Shufen, Y. Ruixiang, T. Shaokun and Q. Can, Comparison of essential oils of clove buds extracted with supercritical carbon dioxide and other three traditional extraction methods, Food Chem., 2007, 101, 1558-1564.

7 L. Quan, S. F. Li, S. J. Tian, H. Xu, A. Q. Lin and L. Gu, Determination of organochlorine pesticides residue in Ginseng root by orthogonal array design Soxhlet extraction and gas chromatography, Chromatographia, 2004, 1, 89-93.

8 D. J. Garkal, S. V. Taralkar, P. Kulkarni, S. Jagtap and A. Nagawade, Kinetic model for extraction of eugenol from leaves of Ocimum sanctum Linn (Tulsi), Int. J. Pharm. Appl., 2012, 3, 267-270.

9 N. Jeyaratnam, A. H. Nour, R. Kanthasamy, A. H. Nour, A. R. Yuvaraj and J. O. Akindoyo, Essential oil from Cinnamomum cassia bark through hydrodistillation and advanced microwave assisted hydrodistillation, Ind. Crops Prod., 2016, 92, 57-66.

10 K. Mostafa, Y. Yadollah, S. Fatemeh and B. Naader, Comparison of essential oil composition of Carum copticum obtained by supercritical carbon dioxide extraction and hydrodistillation methods, Food Chem., 2004, 86, 587-591.

11 E. Schmidt, Production of essential oils, in Handbook of Essential Oils: Science, Technology, and Applications, ed. K. H. C. Baser and G. Buchbauer, CRC Press, Taylor and
Francis Group, Boca Raton, FL, New York, NY, USA, 2010, pp. 83-90.

12 Y. Li, A. S. Fabiano-Tixier and F. Chemat, Essential oils: From conventional to green extraction, in Essential Oils as Reagents in Green Chemistry, Springer International Publishing, 2014, pp. 9-20, DOI: 10.1007/978-3-319-084497.

13 M. T. Golmakani and K. Rezaei, Comparison of microwaveassisted hydrodistillation with the traditional hydrodistillation method in the extraction of essential oils from Thymus vulgaris L., Food Chem., 2008, 109, 925-930.

14 M. A. Vian, X. Fernandez, F. Visinoni and F. Chemat, Microwave hydrodiffusion and gravity, a new technique for extraction of essential oils, J. Chromatogr. A, 2008, 1190, 14-17.

15 F. Chemat, M. E. Lucchesi, J. Smadja, L. Favretto, G. Colnaghi and F. Visinoni, Microwave accelerated steam distillation of essential oil from lavender: a rapid, clean and environmentally friendly approach, Anal. Chim. Acta, 2006, 555, 157-160.

16 J. Gonzalez-Rivera, C. Duce, D. Falconieri, C. Ferrari, L. Ghezzi, A. Piras and M. R. Tine, Coaxial microwave assisted hydrodistillation of essential oils from five different herbs (lavender, rosemary, sage, fennel seeds and clove buds): chemical composition and thermal analysis, Innovative Food Sci. Emerging Technol., 2016, 33, 308-318.

17 D. Chatterjee and P. Bhattacharjee, Supercritical carbon dioxide extraction of eugenol from clove buds, Food Bioprocess Technol., 2013, 6, 2587-2599.

18 N. Gopalakrishnan, P. P. V. Shanti and C. S. Narayanan, Composition of clove (Syzygium aromaticum) bud oil extracted using carbon dioxide, J. Sci. Food Agric., 1990, 50, 111-117.

19 E. Reverchon and C. Marrone, Supercritical extraction of clove bud essential oil: isolation and mathematical modeling, Chem. Eng. Sci., 1997, 20, 3421-3428.

20 Y. Hong-Peng, W. Ke-Gang, W. Tong-Rui, Z. Shao-Shu, C. Xiang- Hua and L. Ze-Hong, Studies on supercritical $\mathrm{CO}_{2}$ extraction-molecular distillation of essential oil from clove (Eugenia caryophyllata Thunb.) bud, Chem. Ind. For. Prod., 2009, 29, 74-78.

21 F. Chemat and M. K. Khan, Applications of ultrasound in food technology: processing, preservation and extraction, Ultrason. Sonochem., 2011, 18, 813-835.

22 L. Alexandru, G. Cravotto, L. Giordana, A. Binello and F. Chemat, Ultrasound-assisted extraction of clove buds using batch- and flow-reactors: a comparative study on a pilot scale, Innovative Food Sci. Emerging Technol., 2013, 20, 167-172.

23 K. Tekin, M. K. Akalın and M. G. Seker, Ultrasound bathassisted extraction of essential oils from clove using central composite design, Ind. Crops Prod., 2015, 77, 954960.

24 B. Yogalakshmi, P. Viswanathan and C. V. Anuradha, Investigation of antioxidant, anti-inflammatory and DNA- 
protective properties of eugenol in thioacetamide-induced liver injury in rats, Toxicology, 2010, 268, 204-212.

25 V. Singh and R. Panwar, In vivo antioxidative and neuroprotective effect of 4-allyl-2-methoxyphenol against chlorpyrifos-induced neurotoxicity in rat brain, Mol. Cell. Biochem., 2014, 388, 61-74.

26 F. M. Rauscher, R. A. Sanders and J. B. Watkins, Effects of isoeugenol on oxidative stress pathways in normal and streptozotocin-induced diabetic rats, J. Biochem. Mol. Toxicol., 2001, 15, 159-164.

27 B. Kiran, V. Lalitha and K. A. Raveesha, Psoralea corylifolia L. a potent medicinal plant with broad spectrum of medicinal properties, Int. J. Fund. Appl. Sci., 2013, 2, 20-22.

28 M. Ito, K. Murakami and M. Yoshino, Antioxidant action of eugenol compounds: role of metal ion in the inhibition of lipid peroxidation, Food Chem. Toxicol., 2005, 43, 461-466.

29 I. Gulcin, Antioxidant Activity of Eugenol: a StructureActivity Relationship Study, J. Med. Food, 2001, 14, 975-985.

30 I. Gulcin, I. G. Sat, S. Beydemir, M. Elmastas and O. I. Kufrevioglu, Comparison of antioxidant activity of clove (Eugenia caryophylata thunb) buds and lavender (Lavandula stoechas L.), Food Chem., 2004, 87, 393-400.

31 K. G. Lee and T. Shibamoto, Antioxidant property of aroma extract isolated from clove buds [Syzygium aromaticum (L.) Merr. et Perry], Food Chem., 2001, 74, 443-448.

32 B. Shan, Y. Z. Cai, J. Brooks and H. Corke, The in vitro antibacterial activity of dietary species and medicinal herb extracts, Int. J. Food Microbiol., 2007, 117, 112-119.

33 S. Hemaiswarya and M. Doble, Synergistic interaction of eugenol with antibiotics against Gram negative bacteria, Phytomedicine, 2009, 16, 997-1005.

34 S. O. Oyedemi, A. I. Okoh, L. V. Mabinya, G. Pirochenva and A. J. Afolayan, The proposed mechanism of bactericidal action of eugenol, $\alpha$-terpineol and $\gamma$-terpinene against Listeria monocytogenes, Streptococcus pyogenes, Proteus vulgaris and Escherichia coli, Afr. J. Biotechnol., 2009, 8, 1280-1286.

35 F. Benencia and M. C. Courreges, In vitro and in vivo activity of eugenol on human herpes virus, Phytother. Res., 2000, 14, 495-500.

36 R. Medzhitov, Origin and physiological roles of inflammation, Nature, 2008, 454, 428-435.

37 L. Ferrero-Miliani, O. H. Nielsen, P. S. Andersen and S. E. Girardin, Chronic inflammation: importance of NOD2 and NALP3 in interleukin-1beta generation, Clin. Exp. Immunol., 2007, 147, 227-235.

38 F. Balkwill, K. A. Charles and A. Mantovani, Smoldering and polarized inflammation in the initiation and promotion of malignant disease, Cancer Cell, 2005, 7, 211-217.

39 D. L. Simmons and C. D. Buckley, Some new, and not so new, anti-inflammatory targets, Curr. Opin. Pharmacol., 2005, 5, 394-397.

40 R. de Cássia da Silveira e Sá, L. N. Andrade and D. P. de Sousa, A review on anti-inflammatory activity of monoterpenes, Molecules, 2013, 18, 1227-1254.
41 C. B. Magalhães, D. R. Riva, L. J. DePaula, A. Brando-Lima, V. L. Koatz, J. H. Leal-Cardoso, W. A. Zin and D. S. Faffe, In vivo anti-inflammatory action of eugenol on lipopolysaccharide induced lung injury, J. Appl. Physiol., 2010, 108, 845-851.

42 S. S. Kim, O. J. Oh, H. Y. Min, E. J. Park, Y. Kim, H. J. Park, Y. N. Han and S. K. Lee, Eugenol suppresses cyclooxygenase-2 expression in lipopolysaccharidestimulated mouse macrophage RAW264.7 cells, Life Sci., 2003, 73, 337-348.

43 T. Koh, Y. Murakami, S. Tanaka, M. Machino and H. Sakagami, Re-evaluation of anti-inflammatory potential of eugenol in IL-1 $\beta$-stimulated gingival fibroblast and pulp cells, In Vivo, 2013, 27, 269-273.

44 X. Huang, Y. Liu, Y. Lu and C. Ma, Anti-inflammatory effects of eugenol on lipopolysaccharide-induced inflammatory reaction in acute lung injury via regulating inflammation and redox status, Int. Immunopharmacol., 2015, 26, 265-271.

45 S. K. Mahapatra, S. Bhattacharjee, S. P. Chakraborty, S. Majumdar and S. Roy, Alteration of immune functions and Th1/Th2 cytokine balance in nicotine-induced murine macrophages: immunomodulatory role of eugenol and $N$-acetylcysteine, Int. Immunopharmacol., 2011, 11, 485-495.

46 M. R. Loizzo, R. Tundis, F. Menichini, A. M. Saab, G. A. Statti and F. Menichini, Antiproliferative effects of essential oils and their major constituents in human renal adenocarcinoma and amelanotic melanoma cells, Cell Proliferation, 2008, 41, 1002-1012.

47 M. Yousefzadi, A. Riahi-Madvar, J. Hadian, F. Rezaee, R. Rafiee and M. Biniaz, Toxicity of essential oil of Satureja khuzistanica: in vitro cytotoxicity and antimicrobial activity, J. Immunotoxicol., 2014, 11, 50-55.

48 S. Rashid, M. A. Rather, W. A. Shah and B. A. Bhat, Chemical composition, antimicrobial, cytotoxic and antioxidant activities of the essential oil of Artemisia indica Willd, Food Chem., 2013, 138, 693-700.

49 S. K. Jaganathan and E. Supriyanto, Antiproliferative and molecular mechanism of eugenol-induced apoptosis in cancer cells, Molecules, 2012, 17, 6290-6304.

50 D. J. Newman and G. M. Cragg, Natural products as sources of new drugs over the last 25 years, J. Nat. Prod., 2007, 70, 461-477.

51 D. M. Noonan, R. Benelli and A. Albini, Angiogenesis and cancer prevention: a vision. Recent results, Cancer Res., 2007, 174, 219-224.

52 F. Kamngar, G. M. Dores and W. F. Anderson, Pattern of cancer incidence, mortality and prevalence across five continents: defining priorities to reduce cancer disparities in different geographic regions of the world, J. Clin. Oncol., 2006, 24, 21-37.

53 D. R. Youlden, S. M. Cramb, C. H. Yip and P. D. Baade, Incidence and mortality of female breast cancer in the Asia-Pacific region, Cancer Biol. Med., 2014, 11, 101-115.

54 M. Pisano, G. Pagnan, M. Loi, M. E. Mura, M. G. Tilocca, G. Palmieri, D. Fabbri, M. A. Dettori, G. Delogu, M. Ponzoni and C. Rozzo, Antiproliferative and pro- 
apoptotic activity of eugenol-related biphenyls on malignant melanoma cells, Mol. Cancer, 2007, 6, 8, DOI: 10.1186/1476-4598-6-8.

55 N. Vidhya and S. N. Devaraj, Induction of apoptosis by eugenol in human breast cancer cells, Indian J. Exp. Biol., 2011, 49, 871-878.

56 M. Behbahani, Evaluation of in vitro anticancer activity of Ocimum basilicum, Alhagi maurorum, Calendula officinalis and their parasite Cuscuta campestris, PLoS One, 2014, 9, e116049.

57 J. P. Noudogbessi, M. Gary-Bobo, A. Adomou, E. Adjalian, G. A. Alitonou, F. Avlessi, M. Garcia, D. C. Sohounhloue and C. Menut, Comparative chemical study and cytotoxic activity of Uvariodendron angustifolium essential oils from Benin, Nat. Prod. Commun., 2014, 9, 261-264.

58 T. Atsumi, S. Fujisawa, K. Satoh, H. Sakagami, I. Iwakura, T. Ueha, Y. Sugita and I. Yokoe, Cytotoxicity and radical intensity of eugenol, isoeugenol or related dimers, Anticancer Res., 2000, 20, 2519-2524.

59 I. Al-Sharif, A. Remmal and A. Aboussekhra, Eugenol triggers apoptosis in breast cancer cells through E2F1/ survivin down-regulation, BMC Cancer, 2013, 13, 600.

$60 \mathrm{H}$. Lee and Y. Wei, Mitochondrial role in life and death of the cell, J. Biomed. Sci., 2000, 7, 2-15.

61 S. K. Jaganathan, A. Mazumdar, D. Mondhe and M. Mandal, Apoptotic effect of eugenol in human colon cancer cell lines, Cell Biol. Int., 2011, 35, 607-615.

62 S. K. Jaganathan, D. Mondhe, Z. A. Wani, H. C. Pal and M. Mandal, Effect of honey and eugenol on Ehrlich ascites and solid carcinoma, BioMed Res. Int., 2010, 2010, $1-5$.

63 A. Hussain, A. Priyani, L. Sadrieh, K. Brahmbhatt, M. Ahmed and C. Sharma, Concurrent sulforaphane and eugenol induces differential effects on human cervical cancer cells, Integr. Cancer Ther., 2012, 11, 154-165.

64 C. Anselmi, M. Centini, M. Andreassi, A. Buonocore, C. L. Rosa, R. M. Facino, A. Sega and F. Tsuno, Conformational analysis: a tool for the elucidation of the antioxidant properties of ferulic acid derivatives in membrane models, J. Pharm. Biomed. Anal., 2004, 35, 1241-1249.

65 S. Hemaiswarya and M. Doble, Combination of phenylpropanoids with 5-fluorouracil as anti-cancer agents against human cervical cancer (HeLa) cell line, Phytomedicine, 2013, 20, 151-158.

66 A. Carrasco, C. Espinoza, V. Cardile, C. Gallardo, W. Cardona, L. Lombardo, M. Catalán, F. Cuellar and A. Russo, Eugenol and its synthetic analogues inhibit cell growth of human cancer cells, J. Braz. Chem. Soc., 2008, 19, 543-548.

67 A. Hussain, K. Brahmbhatt, A. Priyani, M. Ahmed, T. A. Rizvi and C. Sharma, Eugenol enhances the chemotherapeutic potential of gemcitabine and induces anticarcinogenic and anti-inflammatory activity in human cervical cancer cells, Cancer Biother. Radiopharm., 2011, 26, 519-527.
68 M. K. Asha, D. Prashanth, B. Murali, R. Padmaja and A. Amit, Anthelmintic activity of essential oil of Ocimum sanctum and eugenol, Fitoterapia, 2001, 72, 669-670.

69 S. Burt, Essential oils: their antibacterial properties and potential applications in foods-a review, Int. J. Food Microbiol., 2004, 94, 223-253.

70 M. Miyazawa and M. Hisama, Suppression of chemical mutagen-induced SOS response by alkylphenols from clove (Syzygium aromaticum) in the Salmonella typhimurium TA1535/pSK1002, J. Agric. Food Chem., 2001, 49, 4019-4025.

71 G. C. Kim, D. S. Choi, J. S. Lim, H. C. Jeong, I. R. Kim, M. H. Lee and B. S. Park, Caspases-dependent apoptosis in human melanoma cell by eugenol, J. anal. sci. technol., 2006, 39, 245-253.

72 T. Koh, Y. Murakami, S. Tanaka, M. Machino, H. Onuma, M. Kaneko, M. Sugimoto, T. Soga, M. Tomita and H. Sakagami, Changes of metabolic profiles in an oral squamous cell carcinoma cell line induced by eugenol, In Vivo., 2013, 27, 233-243.

73 H. Nam and M. M. Kim, Eugenol with antioxidant activity inhibits MMP-9 related to metastasis in human fibrosarcoma cells, Food Chem. Toxicol., 2013, 55, 106-112.

74 H. Majeed, J. Antoniou and Z. Fang, Apoptotic effects of eugenol-loaded nanoemulsions in human colon and liver cancer cell lines, Asian Pac. J. Cancer Prev., 2014, 15, 91599164.

75 G. Anuj and S. Sanjay, Eugenol: a potential phytochemical with multifaceted therapeutic activities, Pharmacologyonline, 2010, 2, 108-120.

76 G. Tao, Y. Irie, D. Lia and W. M. Keung, Eugenol and its structural analogs inhibit monoamine oxidase $\mathrm{A}$ and exhibit antidepressant-like activity, Bioorg. Med. Chem., 2005, 13, 4777-4788.

77 H. Kabuto, M. Tada and M. Kohno, Eugenol [2-methoxy-4(2-propenyl)phenol] prevents 6-hydroxydopamine induced dopamine depression and lipid peroxidation inductivity in mouse straitum, Biol. Pharm. Bull., 2007, 30, 423-427.

78 S. N. Prasad and M. Muralidhara, Neuroprotective efficacy of eugenol and isoeugenol in acrylamide-induced neuropathy in rats: behavioral and biochemical evidence, Neurochem. Res., 2013, 38, 330-345.

79 D. Garabadu, A. Shah, A. Ahmad, V. B. Joshi, B. Saxena, G. Palit and S. Krishnamurthy, Eugenol as an anti-stress agent: modulation of hypothalamic-pituitary-adrenal axis and brain monoaminergic systems in a rat model of stress, Stress, 2011, 14, 145-155.

80 D. Garabadu, A. Shah, S. Singh and S. Krishnamurthy, Protective effect of eugenol against restraint stressinduced gastrointestinal dysfunction: potential use in irritable bowel syndrome, Pharm. Biol., 2015, 53, 968-974.

81 V. P. Veerapur, K. R. Prabhakar, B. S. Thippeswamy, P. Bansal, K. K. Srinivasan and M. K. Unnikrishnan, Antidiabetic effect of Ficus racemosa Linn. stem bark in high-fat diet and low-dose streptozotocin-induced type 2 diabetic rats: a mechanistic study, Food Chem., 2012, 132, 186-193. 
82 H. Parka, U. J. Junga, S. Choa, H. K. Jungc, S. Shimd and M. Choi, Citrus unshiu peel extract ameliorates hyperglycemia and hepatic steatosis by altering inflammation and hepatic glucose- and lipid-regulating enzymes in db/db mice, J. Nutr. Biochem., 2013, 24, 419-427.

83 U. Palanisamy, T. Manaharan, L. L. Teng, A. K. C. Radhakrishnan, T. Subramaniam and T. Masilamani, Rambutan rind in the management of hyperglycemia, Food Res. Int., 2011, 44, 2278-2282.

84 S. Srinivasan and L. Pari, Antihyperlipidemic effect of diosmin: a citrus flavonoid on lipid metabolism in experimental diabetic rats, J. Funct. Foods, 2013, 5, 484-492.

85 K. Karthikesan, L. Pari and V. P. Menon, Protective effect of tetrahydrocurcumin and chlorogenic acid against streptozotocin-nicotinamide generated oxidative stress induced diabetes, J. Funct. Foods, 2010, 2, 134-142.

86 S. Srinivasan, G. Sathish, M. Jayanthi, J. Muthukumaran, U. Muruganathan and V. Ramachandran, Ameliorating effect of eugenol on hyperglycemia by attenuating the key enzymes of glucose metabolism in streptozotocin-induced diabetic rats, Mol. Cell. Biochem., 2014, 385, 159-168.

87 H. U. Tahir, R. A. Sarfraz, A. Ashraf and S. Adil, Chemical Composition and Anti-diabetic Activity of Essential Oils Obtained from Two Spices (Syzygium aromaticum and Cuminum cyminum), Int. J. Food Prop., 2016, 19, 2156-2164.

88 P. Singh, R. H. Jayaramaiah, S. B. Agawane, G. Vannuruswamy, A. M. Korwar, A. Anand, V. S. Dhaygude, M. L. Shaikh, R. S. Joshi, R. Boppana, M. J. Kulkarni, H. V. Thulasiram and A. P. Giri, Potential dual role of eugenol in inhibiting advanced glycation end products in diabetes: proteomic and mechanistic insights, Sci. Rep., 2016, 6, 1-13, DOI: 10.1038/srep18798.

89 M. A. Morsy and A. A. Fouad, Mechanisms of gastroprotective effect of eugenol in indomethacininduced ulcer in rats, Phytother. Res., 2008, 22, 1361-1366.

90 J. E. Freedman, High-fat diets and cardiovascular disease: are nutritional supplements useful?, J. Am. Coll. Cardiol., 2003, 41, 1750-1752.

91 K. S. Jain, R. R. Kulkarni and D. P. Jain, Current drug targets for antihyperlipidemic therapy, Mini-Rev. Med. Chem., 2010, 10, 232-262.

92 A. L. Amundsen, L. Ose, M. S. Nenseter and F. Y. Ntanios, Plant sterol ester-enriched spread lowers plasma total and
LDL cholesterol in children with familial hypercholesterolemia, Am. J. Clin. Nutr., 2002, 76, 338-344. 93 T. Ichihashi, M. Izawa, K. Miyata, T. Mizui, K. Hirano and Y. Takagishi, Mechanism of hypocholesterolemic action of S-8921 in rats: S-8921 inhibits ideal bile acid absorption, J. Pharmacol. Exp. Ther., 1998, 284, 43-50.

94 W. Shi, M. E. Haberland, M. L. Jien, D. M. Shih and A. J. Lusis, Endothelial responses to oxidized lipoproteins determine genetic susceptibility to atherosclerosis in mice, Circulation, 2000, 102, 75-81.

95 D. L. Tribble, Antioxidant consumption and risk of coronary heart disease: emphasis on vitamin C, vitamin E, and $\beta$-carotene, Circulation, 1999, 99, 591-595.

96 E. Hopps, D. Noto, G. Caimi and M. R. Averna, A novel component of the metabolic syndrome: the oxidative stress, Nutr., Metab. Cardiovasc. Dis., 2010, 20, 72-77.

97 M. M. Duarte, J. B. Rocha, R. N. Moresco, T. Duarte, I. B. Da Cruz, V. L. Loro and M. R. Schetinger, Association between ischemia-modified albumin, lipids and inflammation biomarkers in patients with hypercholesterolemia, Clin. Biochem., 2009, 42, 666-671.

98 K. Srinivasan, Antioxidant potential of spices and their active constituents, Crit. Rev. Food Sci. Nutr., 2014, 54, $352-372$.

99 K. Venkadeswaran, A. R. Muralidharan, T. Annadurai, V. V. Ruban, M. Sundararajan, R. Anandhi, P. A. Thomas and P. Geraldine, Antihypercholesterolemic and antioxidative potential of an extract of the plant, Piper betle, and its active constituent, eugenol, in Triton WR1339-induced hypercholesterolemia in experimental rats, J. Evidence-Based Complementary Altern. Med., 2014, 2014, 1-11, DOI: 10.1155/2014/478973.

100 A. Munisa, W. Manalu, T. Wresdiyati and N. Kusumorini, The Effect of Clove Leaf Methanol Extract on the Profiles of Superoxide Dismutase and Malondialdehyde in the Liver of Rabbits under Hypercholesterolemia Condition, Transl. Biomed., 2015, 6, 1-5, DOI: 10.21767/21720479.100012.

101 S. Jin and K. H. Cho, Water extracts of cinnamon and clove exhibits potent inhibition of protein glycation and antiatherosclerotic activity in vitro and in vivo hypolipidemic activity in zebra fish, Food Chem. Toxicol., 2011, 49, 15211529. 